Ath-Thariq, No. 01, Vol. 02 Juli-Desember 2017

\title{
MANAJEMEN KONFLIK DALAM FILM MY NAME IS KHAN PERSPEKTIF KONSEP DAKWAH
}

\author{
Robby Aditya Putra, M.A \\ Institut Agama Islam Negeri Metro Lampung \\ robbyadityaputra@gmail.com)
}

\begin{abstract}
History records a series of realities of conflict in the archipelago. The conflict in Sampit 2011, for example, happened due to misscommunication between ethnic Madura and Indigenous Dayak communities. SARA conflict in Maluku and Poso 1999-2001. Tragic and heartbreaking. Ideally, such conflicts need not be staged, even take victims. Given that no religion teaches it. But conflict is a necessity. Therefore, expertise in conflict management needs to be emphasized. This paper examines conflict management in the movie My Name is Khan (2010) viewed from the perspective of the three concept of da'wah (An-Nahl: 125). (1) Bil Hikmah (2) Al-Mauidzah al-hasanah (3) Al-Mujadalah. Thesis statement from this paper, My Name is Khan is a fairly mature Islamic film. With the jargon of My Name is Khan, and I am not a Terrorist, Director Karan Kapoor managed to present this slick film as a representation to end the conflict that includes Bil Hikmah, Al-Mauidzah al-hasanah and Mujadalah. But unfortunately, this film also contains about the excessive pluralis.
\end{abstract}

\section{A. PENDAHULUAN}

Intinya, tujuan manusia saling berkomunikasi adalah untuk merubah sikap, pendapat dan prilaku guna menciptakan kehidupan yang damai dan tentram. Memang pernyataan ini terlihat terburu-buru menyimpulkan. Tapi memang begitu adanya. Lagipula siapa yang menyangkal pernyataan tersebut? Burhan Bungin dalam bukunya Sosiologi Komunikasi menyebut William Ogburn, Meyer Nimkoff dan Pitirim Sorokim mengamini bahwa komunikasi dilaksanakan agar tercipta sistem kehidupan yang baik. ${ }^{1}$ Juga Donald W. Klopf dan James C. McCroskey menganggap, jika komunikasi antar budaya dilakukan dengan rasa saling memahami, maka perdamaian akan ada di mana-mana. ${ }^{2}$ Jadi, komunikasi itu penting. Tak heran jika Charles Atkin berkata bahwa manusia tidak bisa tidak berkomunikasi. ${ }^{3}$

1 Burhan Bungin, Sosoilogi Komunikasi (Jakarta: Kencana, 2006), 23-30.

2 Donald W. Klopf and James C. McCroskey, Intercultural Communication Encounters (Boston: Pearson and AB, 2007), 45-47.

${ }^{3}$ Charles Atkin, Human Communication Principles, Contexts and Skills (New York: Martin Press, 1980), 6.

Manajemen Konflik Dalam Film My Name ....

Robby Aditya Putra 
Terlepas dari pernyataan di atas, konflik justru punya celah untuk tumbuh dalam nafas manusia, ketika mereka dipandang sebagai makhluk sosial yang saling berkomunikasi. Diakui oleh Leung dan Tjosvold bahwa keanekaragaman atau kebhinekaan disatu pihak dapat juga menimbulkan ancaman bagi keutuhan persatuan dan kesatuan suatu bangsa. ${ }^{4}$ Apalagi jika ditinjau dari obyektif alamiah, kondisi wilayah dan bangsa Indonesia yang majemuk mempunyai dua mata pisau, bisa jadi kelebihan atau bahkan berpotensi konflik. ${ }^{5}$

Sejarah mencatat sederatan konflik yang tergelar di dunia dan Indonsia. Konflik di Sampit 2011, misalnya, yang terjadi karena misscommunication antara etnis Madura, sebagai warga pendatang, dengan masyarakat asli Dayak. Konflik bernuansa SARA di Maluku, Ambon dan di Poso, Sulawesi Tengah tahun 1999-2001. Pilu, tragis dan menyedihkan. Apalagi konflik 9/11 menimpa gedung WTC yang menggemparkan dunia.

Padahal, tidak ada satu agama pun yang melegitimasi terhelat nya konflik. Dalam Islam, eksistensi kebangsaan dan kesukuan secara eksplisit diakui sebagai takdir yang tidak bisa diingkari. Berbangsa dan bersuku-suku supaya saling mengenali dan berbuat kebaikan satu sama lain.

"Hai manusia, sesungguhnya Kami menciptakan kalian dari seorang laki-laki dan seorang perempuan, serta menjadikan kalian berbangsa-bangsa dan bersuku-suku supaya kalian saling mengenal. Sesungguhnya orang yang paling mulia di antara kalian di sisi Allah ialah orang yang paling takwa. Sesunggguhnya Allah Maha Mengetahui lagi Maha Mengenal" (QS al-Hujurat [49]: 13). ${ }^{6}$

Tapi, konflik adalah sebuah keniscayaan. Karena konflik merupakan komponen yang tidak bisa dihindari ketika manusia masih hidup. ${ }^{7}$ Oleh karena itu, diperlukan manegemen yang handal untuk memositifkan konflik.

Di sisi lain, seiring berkembangnya globalisasi di dunia, penyebaran informasi menjadi cepat dan mudah. Salah satu produk globalisasi adalah film. Film sering dikaitkan sebagai media hiburan, pendidikan, propaganda bahkan juga sebagai alat perpolitikan. Film jarang dikatakan sebagai media dalam menengahi konflik, karena memang minimnya film-film bergenre ini

4 Kwok Leung and Dean Tjosvold, Conflict Manajement in the Asia Pacific (Singapure: John Wiley and Sons, 1998), 86-89.

5 Budisantoso. S., Ketahanan Nasional Indonesia (Jakarta: Pustaka Sinar Harapan, 2001), 29-34.

6 Departemen Agama RI, Al-Qur'an dan Terjemahannya (Jakarta: Bumi Restu, 1976), 14.

7 Kreitner, R. and Kinicki, A , Organitational Behavior (New York: McGraw-Hill, 2010), 7 .

Manajemen Konflik Dalam Film My Name .... 
diproduksi. Padahal, para filmmaker Indonesia sudah diberikan kebebasan berkreasi dan berinovasi dalam memproduksi film.

Dalam film My Name is Khan, konflik bermula ketika kejadian tragis yang menimpa menara WTC pada 11 September 2001. Setelah kejadian itu, mahligai pernikahan Rizwan (Sah Ruk Khan) dan Mandira (Kajol) di ujung tanduk, setelah Mandira kehilangan putranya Sameer yang dianiaya segerombolan pemuda kulit putih, yang terjadi karena nama akhiran muslim "Khan" dianggap pembawa bencana, Rizwan, sebagai muslim, diusir dari rumah oleh Mandira, dan hanya bisa kembali setelah ia bertemu presiden Amerika Serikat.

Dari sinilah perjalanan Rizwan dimulai untuk memperjuangkan keadilan. Rangkaian perjalanan tokoh utama dalam film ini memuat unsur-unsur manajemen konflik yang menarik untuk digali lebih dalam. Dan dapat dijadikan represenasi dalam menyudahi konflik di Indonesia.

\section{B. KONFLIK}

Beberapa ahli memaknai konflik dalam beberapa pengertian. Kreitner dan Kinicki mengatakan bahwa konflik adalah suatu kondisi apabila seseorang, ataupun organisasi mempunyai pandangan, keinginan, dan persepsi yang tidak sama dengan yang lain. ${ }^{8}$ Conflict di dalam bahasa aslinya berarti suatu perkelahian, peperangan, atau perjuangan, yaitu berupa perbedaan kepentingan, atau suatu kepercayaan bahwa aspirasi pihak-pihak yang berkonflik tidak dapat dicapai secara simultan. ${ }^{9}$ Dalam sudut pandang komunikasi, konflik baru dianggap suatu konflik jika hal tersebut telah diekspresikan ke dalam proses komunikasi. ${ }^{10}$

Dari uraian tersebut, dapat disimpulkan bahwa, konflik adalah suatu kondisi saat miscommunication terjadi, sehingga berkonsekuensi pada sikap, pendapat dan prilaku antara dua belah pihak berlainan.

Sebenarnya, jika diperhatikan, konflik adalah keniscayaan. Konflik merupakan komponen yang tidak bisa dihindari ketika manusia masih bergerilya di bumi.11 Oleh karena itu, kemampuan pengelolaan/manajemen konflik sangat penting dan berpengaruh terhadap situasi dan kondisi.

Rahim, Garret dan Buntzman mengatakan bahwa ada lima cara dalam mengelola konflik, yaitu dominasi, kompromi, integrasi,

8 Kreitner, R. and Kinicki, A , Organitational Behavior (New York: McGraw-Hill, 2010), 7.

9 Kadarman, Pengantar Ilmu Manajemen (Jakarta: Prenhallindo, 2001), 17.

10 Robby I. Chandra, Konflik dalam Kehidupan Sehari-hari (Yogyakarta: Kanisius, 1998), 49.

11 Kreitner, R. and Kinicki, A , Organitational Behavior (New York: McGraw-Hill, 2010), 7.

Manajemen Konflik Dalam Film My Name ....

Robby Aditya Putra 
menghindari dan obligasi. Sebagaimana yang dapat terlihat pada bagan di bawah ini:

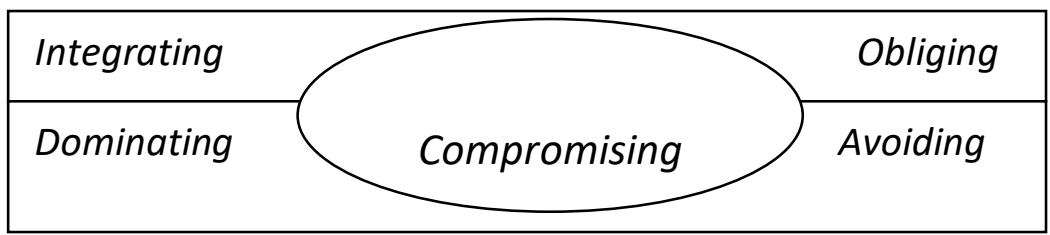

Dari bagan tersebut dapat dijelaskan sebagai berikut:

a. Integrating: di dalam cara yang pertama ini, kedua pihak duduk bersama dan secara kooperatif mengidentifikasi masalah, membentuk alternatif-alternatif yang mungkin dibentuk, dan memilih solusi yang paling tepat. Cara ini kurang tepat dilakukan jika konflik yang terjadi menyangkut kesalahan sistem.

b. Obliging: cara kedua yang dapat dilakukan menggunakan cara obliging, yaitu salah satu pihak mengalah kepada pihak lain. Pihakpihak yang bersangkutan lebih mengedepankan kesamaan dibandingkan perbedaan. Cara ini cocok jika pihak yang mengalah mendapatkan imbalan.

c. Dominating: cara ini dilakukan jika salah satu pihak mementingkan dirinya dan membuat pihak lain kalah dalam konflik tersebut. Jika salah satu pihak mementingkan dri sendiri, maka dominating adalah cara yang tepat.

d. Avoiding: Cara sealnjut nya adalah kedua belah pihak menghindari pembahasan tentang konflik yang sedang berlangsung. Cara ini baik, namun kekurangannya konflik akan datang kembali di kemudian hari jika kedua belah pihak kembali meradang.

e. Compromising: Cara ini merupakan penyelesaian koflik kedua belah pihak harus memberi dan menerima kelebihan dan kekurangan masing-masing. Cara inilah yang populer digunakan dalam memanajemen konflik. ${ }^{12}$

Sedangkan mengikuti kemauan orang lain berarti gaya yang mengikuti kemauan orang lain berusaha sejauh mungkin menyembunyikan sejauh mungkin perbedaan di antara pihak-pihak yang terlibat dan mencari titik persamaan. Gaya ini dapat digunakan secara efektif dengan cara memelihara hubungan baik, sedangkan dilihat dari segi negatifnya seolah

12 Rahim, M.A., Garret, J.E., and Buntzman, G. F. Ethics of Menaging Interpersonal Conflict in Organization. Journal of Business Ethics, No. 11 Vol. 56, 1992, 423-432, dalam, Reno Grivaldi, Analisis Perbedaan Manajemen Konflik Manajer Jepang dan Manajer Indonesia Indonesia (Jakarta: UI Press, 2012), 12-14. 
orang lain akan berasumsi mempersilahkan seseorang untuk memperlakukan dia semau hatinya.

Dalam konteks komunikasi, konflik dan hubungan manusia terjadi karena adanya proses komunikasi. Komunikasi terjadi karena adanya bahasa dan pikiran manusia. Sehingga, satu-satunya cara memanajemen konflik itu sendiri adalah dengan berkomunikasi. ${ }^{13}$ Jadi, seni kemampuan komunikasi menjadi bagian penting dalam mengubah konflik destruktif menjadi konflik yang fungsional dan bermanfaat bagi keduanya.

Di lain sisi, sejak dahulu, film sudah dijadikan alat untuk mengubah persepsi penonton. Selama perang dunia ke II, militer AS memanfaatkan film sebagai bahan materi dalam pelatihan dan motivasi para tentaratentara AS. Film berjudul The Battle of Britian dan Why We Fight, produksi Frank Capra, adalah dua film yang dijadikan bahan riset oleh Hovland, Lumsdaine, dan Sheffield. ${ }^{14}$ Artinya, film mempunyai cara unik dalam merespon dan mewarnai perjalanan panjang fenomena dunia dan sebuah negara. Termasuk My Name is Khan (2010) yang sedang diteliti, film ini menyajikan cara lain dalam menyudahi konflik.

\section{Konsep dan Metodologi}

\section{a. Konsep}

Konsep yang dipakai dalam tulisan ini adalah konsep dakwah sesuai surat An-Nahl: 125, yang berbunyi:

Serulah (manusia) kepada jalan Tuhan-mu dengan hikmah dan pelajaran yang baik dan bantahlah mereka dengan cara yang baik. Sesungguhnya Tuhan-mu Dialah yang lebih mengetahui tentang siapa yang tersesat di jalan-Nya dan Dialah yang lebih mengetahui orang-orang yang mendapatkan petunjuk. (An-Nahl: 125).

Ada tiga konsep yang ditekankan dalam ayat diatas, yaitu (1) Bil Hikmah (2) Al-Mauidzah al-hasanah (3) Al-Mujaadalah.

Pertama, Bil Hikmah. Kata Bil Hikmah, secara sederhana artinya alilmu (ilmu pengetahuan), al-haq (kebenaran, al-adil (keadilan), al-Sabru (Sabar), falsafah, kebijakan, pemikiran. Sedangkan secara umum, Bil Hikmah, yaitu berdakwah dengan memperhatikan dan mengamati situasi dan kondisi objek dakwah dengan menitik-beratkan pada kemampuan mereka. Atau kemampuan para praktisi amar ma'ruh nahi munkar dalam memilah, memilih dan menyelaraskan dengan kondisi objektif mad'u. ${ }^{15}$ Sehingga dalam konteks manajemen koflik, diartikan

13 Robby I. Chandra, Konflik dalam Kehidupan Sehari-hari (Yogyakarta: Kanisius, 1998), 99-101.

14 Hovland, C.I., A.A Lumsdaine, and F.D. Sheffield, Experiments on Mass Communications (Newyork: Wiley, 1949), 167-190.

15 M. Munir, Metode Dakwah (Jakarta: Kencana, 2009), 10-11.

Manajemen Konflik Dalam Film My Name .... 
sebagai kemampuan seseorang dalam menghubungkan kondisi lapangan dengan diksi yang akan dipilih.

Kedua, Al-Mauidzah al-Hasanah. Ungkapan Al-Mauidzah al-Hasanah, artinya nasihat, simbol, tanda, bimbingan, pengajaran, alamat, dan lemah-lembut. Dan makna secara umum, Al-Mauidzah al-Hasanah yaitu penyampaian pesan dengan memberikan nasihat-nasihat dengan cara ramah. Sehingga nasihat dan pengajaran pesan yang disampaikan dapat menyentuh hati nurani mereka. ${ }^{16}$ Dalam konteks manajemen konflik, Al-Mauidzah al-Hasanah merupakan kemampuan seseorang dalam menasehati pihak konflik. Sehingga inti dari pesan dapat diterima secara kognitif, afektif dan psikomotorik, tanpa membongkar dan membeberkan kesalahan orang lain secara berlebihan.

Ketiga, Al-Mujadalah. Istilah Al-Mujadalah, artinya debat, diskusi dan bantahan (argumen) yang lebih baik. ${ }^{17}$ Dalam konteks mengelola konflik, berarti tukar pendapat yang dilakukan kedua belah pihak secara sinergis, saling menghargai dan menghormati, megakui kebenaran pihak lain dan ikhlas menerima hukuan kebenaran tersebut.

Bingkai Konsep

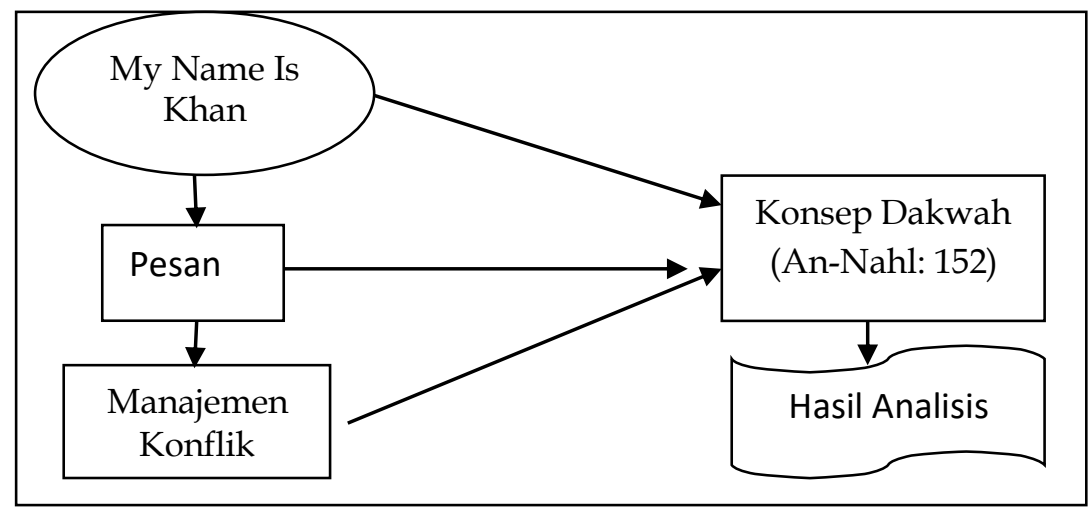

Bingkai konsep di atas dapat membantu menjelaskan skema dalam tulisan ini. Film My Name is Khan akan di analisis pesan-pesannya dari perspektif konsep dakwah. 3 Konsep dakwah akan dijadiakan alat ukur untuk mengukur nilai-nilai manajemen konflik dari film tersebut. Setelah itu, hasil yang didapat akan di analisis, kemudian akan dikontruksikan menjadi sebuah refleksi dan pernyataan akhir.

b. Metodelogi

Tulisan ini menekankan objek penelitiannya pada gejala-gejala sosial yang memiliki gejala majemuk, dan berbeda dengan gejala alam yang

16 M. Munir, Metode Dakwah.........359-367.

17 Moh Ali Aziz, Ilmu Dakwah (Jakarta: Kencana, 2009.Rev.ed), 359-5. 
lebih mempunyai regularitas. ${ }^{18}$ Fokus makalah ini tentang manajemen konflik yang disajikan lewat film My Name is Khan dilihat dari perspektif konsep dakwah. Penelitian terkait film My Name is Khan ini merupakan penelitian tentang media massa. Film merupakan salah satu bentuk dari media massa. Komunikasi massa melibatkan penggunaan media massa, berupa media cetak, seperti surat kabar dan majalah, media elektronik seperti film, televisi, radio dan internet, untuk berkomunikasi dengan banyak orang pada saat bersamaan.

\section{Analisis}

Bagian ini akan fokus untuk melihat manajemen konflik dari film $M y$ Name is Khan perspektif konsep dakwah, sesuai dengan pertanyaan mayor, yaitu bagaimanakah manajemen konflik dalam film My Name is Khan jika dilihat dari perspektif konsep dakwah? Selanjutnya, narasi besar ini akan dijabarkan melalui pertanyaan yang lebih spesifik seperti, apakah setiap adegan dalam film My Name is Khan mengandung unsur hikmah? Dengan apa film ini menyajikan adegan-adegan yang memuat pengajaran yang baik? Serta apa saja perdebatan-perdebatan baik yang ingin disampaikan? Teori konsep dakwah diharapkan dapat menjadi alat untuk meneropong lebih dalam manajemen konflik film My Name is Khan.

\section{a) Bil-Hikmah}

Selama 155 menit, film My Name is Khan menyuguhkan adegan-adegan terkait bagaimana cara menyudahi konflik secara hikmah. Aksi teroris 11 September 2001 telah mengguncang dan mengubah kehidupan beragama pada level dunia. Hubungan Barat dan dunia Islam menjadi saling berhadapan, bukannya berkoalisi membangun peradaban yang maju dan damai.

Di sebuah masjid, ketika hendak menenangkan diri, Rizwan menjumpai sekelompok orang yang tengah didoktrin seorang perekrut teroris. Rizwan tak tinggal diam. Dia membantah semua ucapan sang teroris dengan berdalih bahwa jalan Islam adalah kasih sayang, bukan kebencian dan perang. Langkah selanjutnya, dia melaporkan keberadaan Faisal Rehman si perekrut teroris kepada FBI. Sayang, tak ada tanggapan positif dari FBI. Dalam menit ke 45.00 ini, tokoh utama berusaha memberikan penjelasan terkait wajah Islam yang damai, bukan radikal. Ilmu yang kita punya sebaiknya digunakan untuk mengelelola konflik agar kian membaik. Bukan malah memprovokasi khalayak untuk memperbesar jembatan konflik. Berikut dialog adegan ketika menit 45.00:

Dr. Faisal Rahman: "Dengan saudara- saudaraku, tidak ada masalah dengan kristen atau yahudi. Nyatakan aku juga tidak ada masalah dengan saudarasaudara hindu. Aku banyak merawat pasien hindu di rumah sakit St. Benedic.

18 Burhan Bungin, Metodologi Penelitian Kuantitatif (Jakarta: Kencana, 2008), 31-33. 
Aku cuma marah ketika kebaikan ini tidak timbal balik kepada kita muslim. Darahku mendidih ketika Yahudi Israel menindas saudara-saudara kita di Palestina. Atau ketika orang-orang hindu di India membantui wanita-wanita dan anak-anak kita dengan pedang mereka. Ketika itulah darahku mendidih. Jadi lakukan sesuatu, aku Dr. Faisal Rahman bersumpah bahwa aku sudah siap. Apakah kalian siap??" Pemuda kemudian menjawab: "Aku siap..aku siap..!!" Dr. Faisal Rahman menyulut api kebencian mereka dengan menjawab: "ini tuntutan Allah!! Ini tuntutan islam!!"

Mendengar cermaha provokasi Dr. Faisal Rahman, Rizwan kemudian menyangkalnya sembari berkata: "tidak..tidak..kau pendusta."

Dr. Faisal Rahman lalu menjawab: "kenapa saudara? Apakah saudara tidak percaya dengan pengobatan Ismail?"

Rizwan: "tidak, ibuku pernah menyampaikan kisah Nabi Ibrahim AS tidak pernah ragu dalam melaksanakan perintah Tuhan. Kisah itu adalah contoh kekuatan iman dan keyakinan." Ibuku berkata, "Rizwan, kisah ini menunjukan jalan Allah adalah jalan kasih sayang, bukan kebencian dan perang."

Pemuda: "dia benar!!" (menunjukan kepada Rizwan).

Lebih lanjut mengenai scene permenit film My Name is Khan terkait konsep bil-hikmah dapat dilihat pada gambar di bawah ini:

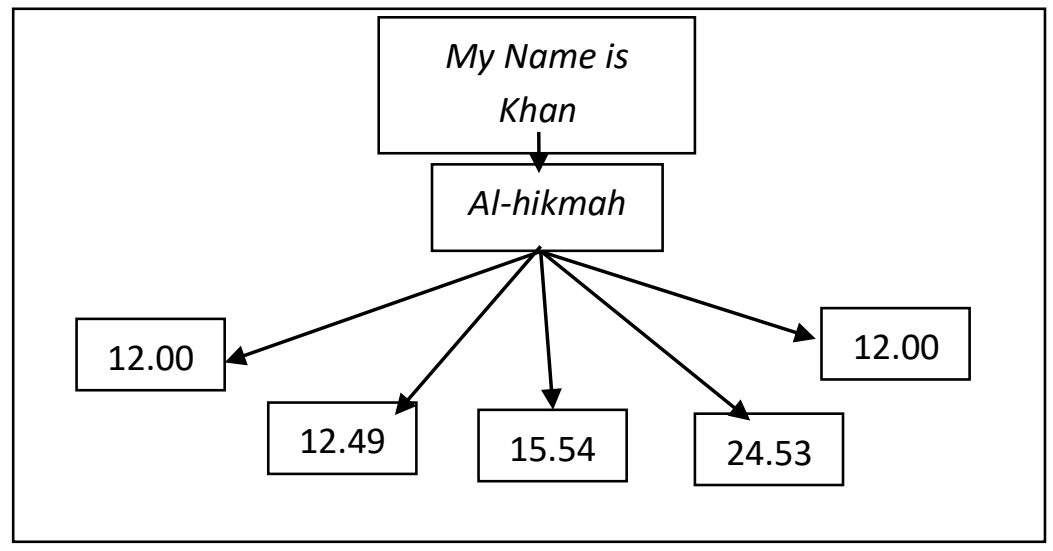

b) Al-Mauidzah al-Hasanah.

Dalam cerita film ini, beruntung Rizwan Khan kecil memiliki seorang ibu yang dengan bijaksana berusaha menjelaskan bahwa di dunia ini hanya ada tipologi, pertama orang baik dan kedua orang buruk, tidak peduli apapun suku, agama, ras, dan golongannya. Khan dan Mandira telah berusaha menjembatani hubungan Islam dan agama lain yang saling mencurigai dan membenci pasca 9/11. Lewat sosok Khan, film ini berhasil menampilkan ajaran Islam yang peduli pada penderitaan sesamanya dengan nasehat-nasehat yang baik.

Pada menit 12.05, ada adegan yang menampilkan di mana Rizwan kecil mendengar percakapan penuh kebencian di jalan di suatu daerah yang kumuh, api menyala nyala dan orang-orang yang berkumpul 
yang nampak waspada, seperti itulah lingkungan masa kecil Rizwan digambarkan dalam film ini. Kesan kumuh sudah tampak pada jalanan yang berantakan dan sudut pandang yang diambil dari balik sebuah gerobak. Setting waktu yang diambil adalah ketika terjadi bentrokan antara umat muslim dan hindu pada tahun 1983 di India. Digambarkan juga ibu Rizwan yang sedang menasehati Rizwan dengan konsep manusia dan menanamkan nilai kebaiakan keburukan juga persamaan hakekat tiap manusia.

Lebih lanjut mengenai scene My Name is Khan perspektif konsep Al-Mauidzah al-Hasanah dapat dilihat pada gambar di bawah ini:

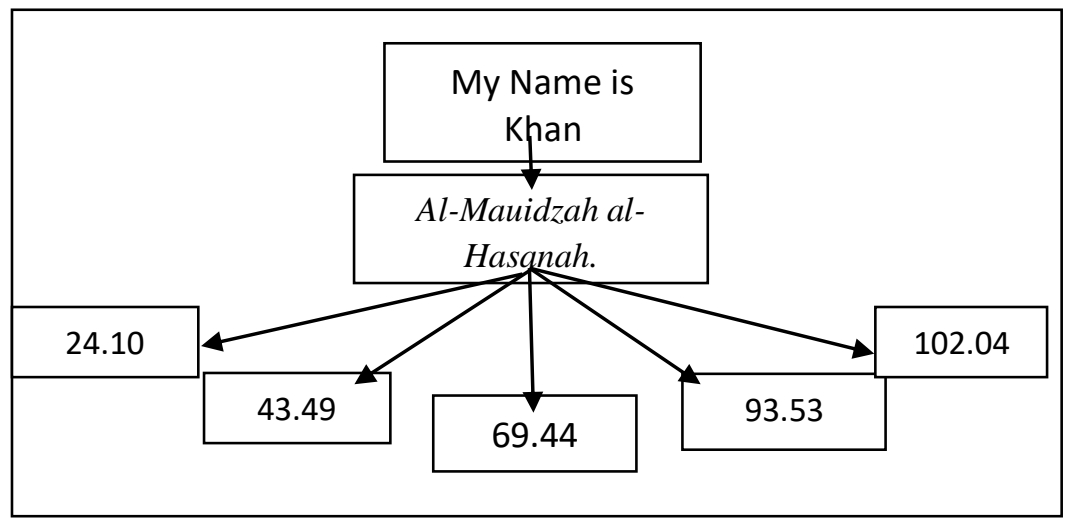

\section{c) Al-Mujadalah}

Pembuktian Rizwan bahwa dia bukan teroris diakui presiden Obama. Digambarkan Rizwan berhasil ketika presiden Obama berkuasa karena dia merupakan presiden yang memiliki misi untuk menghentikan konflik di Irak. Sebelum pada masa presiden Bush, Rizwan tidak berhasil menemuinya dan ditangkap karena diduga seorang teroris. Film ini meski ada nuansa dakwah dan misinya dalam menolak anggapan negatif terhadap muslim pascaperistiwa 11 September 2001, tetap saja ada motif komersialnya.

Sebenarnya banyak cara untuk menegaskan kepada dunia bahwa Islam bukana agama yang mendukung terorisme, tapi disini Rizwan memilih untuk menegaskan hal tersebut kepada orang nomor satu di dunia yaitu Barrack Obama dengan tujuan agara Barrack Obama mengumumkan kepada dunia bahwa Islam tidak mengajarkan terorisme, inilah cara demokratis yang dia tempuh, inilah cara perdebatan yang baik yang dia tempuh, untuk menepis gambaran negatif terhadap Islam dan menegaskan bahwa terorisme atau radikalisme bukan dari bagian ajaran Islam.

Penghormatan, pengakuan kebenaran pihak lain dan ikhlas menerima kebenaran tersebut. Inilah yang dilakukan Rizwan yang 
secara ekplisit sutradara Karan Johar ingin menggunakan model Compromising, di mana cara ini merupakan penyelesaian koflik kedua belah pihak harus memberi dan menerima kelebihan dan kekurangan masing-masing.

Dalam film ini setidaknya ada 12 scene/adegan yang sesuai dengan 3 konsep dakwah. (1) Bil Hikmah (2) Al-Mauidzah al-hasanah (3) Al-Mujadalah. Sebagai salah satu bentuk media massa, film ini ingin berkontribusi dalam merefleksikan pentingnya perdamaian bagi manusia. Refleksi ini di rasa penting, ditengah kemajemukan Indonesia. Seperti yang sudah diungkapkan dalam bab sebelumnya bahwa kemajemukan bermata dua pisau, bisa menjadi keuntungan untuk kemajuan, juga bisa sebagai bencana.

\section{KESIMPULAN}

Konsep Islam anti kekerasan dimunculkan dalam film ini dengan baik, Kemampuan memanejemen konflik pun teruarai secara jelas. Meskipun yang ditonjolkan hanya dari sisi akhlak saja. Hal ini cukup beralasan, menurut penulis, jika film ini menggemakan akidah dan ibadah juga, kemungkinan agak sulit dipasarkan di India sendiri apalagi di Barat (Amerika dan Eropa), sementara sasarannya adalah dunia Barat non muslim. Jadi terpaksalah Karan Johar sebagai sutradara film ini tidak menonjolkan Islam dari sisi akidah dan ibadah, hanya dari sisi akhlaknya saja. Padahal akidah dan ibadah tentu merupakan pesan agama Islam yang sangat penting. Hal ini cukup beralasan karena industry film memang membutuhkan dana yang tidak sedikit. Dana adalaj jantung, yang dapat membuat crew film memproduksi film selanjutnya. Apalgi film ini diproduksi dibeberapa negara.

Film ini memberikan gambaran sikap Islam terhadap aksi terorisme yang sedang marak dengan cara dakwah yang hikmah, tidak banyak menggurui tapi membiarkan penonton untuk mendapatkan nilai-nilai kebaikan dari Islam tersebut dari beberapa makna tersirat, yang dimunculkan beberapa episode film. Selain Bil-Hikmah, Al-Mauidzah alhasanah, Al-Mujadalah juga turut dikemas dengan lezat. Namun, film ini juga nampak kebablasan dari segi toleransi, karena membuat adegan pernikahan seorang muslim dengan non-muslim. Sutradara Karan Johar terlalu berani memilih adegan perkawinan silang ini, yang mengakibatkan kekurangmatangan film ini menjadi begitu menonjol.

Disinilah pentingnya wacana kerukunan umat beragama selalu penting untuk diperhatikan, karena ibarat bom waktu yang sewaktu-waktu bisa meledak. bila pemicunya dipetik oleh oknum yang tidak bertanggungjawab. Peranan media massa, film, dalam hal ini perlu dioptimalkan dari waktu-kewaktu. 
Banyak "sekolah" yang mengajarkan agar manusia menjadi manusia seutuhnya. Manusia yang saling memahami dan mengasihi. Buku, pengalaman, kisah hidup, sejarah, anak kecil, film dan lainnya. Seperti yang sudah dibahas pada bagian pembahasan, bahwa konflik adalah sebuah keniscayaan. Tidak ada manusia yang masih bernafas yang tidak memiliki konflik. Konflik pribadi, keluarga ataupun kantor. Hanya mayat saja bebas dari konflik dunia. Film ini merupakan salah satu tempat belajar untuk menjadi rujukan mangelola konflik. Namun tentu saja tetap harus direlevansikan dengan ajaran agama-agama samawi.

\section{DAFTAR PUSTAKA}

Atkin, Charles. Human Communication Principles, Contexts and Skills. New York: Martin Press, 1980.

Aziz, Moh Ali, Ilmu Dakwah. Jakarta: Kencana, 2009.

Berger, Peter L. dan Thomas Luckmann, "The Social Construction of Reality: A treatise in the Sociology of Knowledge", 1966.

Branston, Gill and Roy Stafford. The Media Student's Book. London and New York: Routledge, 2003.

Budisantoso. S. Ketahanan Nasional Indonesia. Jakarta: Pustaka Sinar Harapan, 2001.

Bulaeng, Andi. Metode Penelitian Komunikasi Kontemporer (Jogjakarta: Andi, 2004. Bungin, Burhan. Sosoilogi Komunikasi. Jakarta: Kencana, 2006.

Chandra, Robby I. Konflik dalam Kehidupan Sehari-hari. Yogyakarta: Kanisius, 1998.

Departemen Agama RI, Al-Qur'an dan Terjemahannya. Jakarta: Bumi Restu, 1976.

Dixon, Wheeler Winston, “Teaching Film after 9/11," Cinema Journal, Vol. 43, No. 2 (2004).

Gaus, Ahmad AF, Media Alternatif, dalam Media dan Integrasi Sosial: Jembatan antar Umat Beragama. Jakarta: CSRC UIN, Mei 2011.

Grivaldi, Reno. Analisis Perbedaan Manajemen Konflik Manajer Jepang dan Manajer Indonesia Indonesia. Jakarta: UI Press, 2012.

Hovland, C.I., A.A Lumsdaine, and F.D. Sheffield, Experiments on Mass Communications. Newyork: Wiley, 1949), 167-190.

Jauhari, Haris. "Layar Membentang (1900-1942)" dalam Haris Jauhari (ed.), Layar Perak 90 Tahun Bioskop di Indonesia. Jakarta: Gramedia Pustaka Utama, 1992.

Kadarman, Pengantar Ilmu Manajemen. Jakarta: Prenhallindo, 2001. 